Madrygal. Revista de Estudios Gallegos

ISSN: 1138-9664

\title{
1906-2006: centenario de la Real Academia Gallega ${ }^{1}$
}

Victoria Álvarez Ruiz de Ojeda

Muchas gracias por estas palabras tan cordiales y de la misma forma agradezco a la comisión organizadora de este encuentro cultural la invitación que me ha hecho, la cual me ha permitido volver a La Habana, ciudad en la que yo ya he estado con anterioridad. Aunque, en verdad, yo puedo decir que nunca vuelvo a Cuba, porque la llevo conmigo. En esto no soy especial: es que nosotros, los gallegos, siempre llevamos a Cuba con nosotros.

Muchas gracias también a nuestros anfitriones, que nos honran recibiéndonos en esta casa, el Centro Cultural Dulce María Loynaz, de la Academia Cubana de la Lengua.

Como tema para mi intervención se me ha designado "1906-2006: centenario de la Real Academia Gallega", tema con el que me siento muy a gusto, pues desde hace años vengo estudiando y escribiendo sobre la historia de la Academia Gallega.

Pero yo debo hablar sobre la Academia aquí $\mathrm{y}$ ahora (hic et nunc): aquí, en Cuba, donde, como todos ustedes saben, nació la academia Gallega pronto hará cien años.

En estos casi cien años la RAG ha protagonizado muchas actividades, ha editado y patrocinado innumerables publicaciones, a ella han pertenecido muchas ilustres personalidades. Cien años no se pueden sintetizar en los términos convenidos de los pocos minutos que debe durar mi intervención. Es obligado, pues, seleccionar, y ya que hablamos aquí, en Cuba, quizá sea razonable insistir en la relación de Cuba con la Academia Gallega.
Ante todo hay que formularse una pregunta: ¿qué sentido tiene la Real Academia Gallega? Sea o no oficial una lengua, hay un momento de su historia en que sus cultivadores llegan a la conclusión de que es imprescindible una norma que sustente la unidad del idioma. La unidad lingüística de un idioma se sustenta en un triple código: ortografía, gramática y diccionario. Es decir, es preciso un criterio ortográfico válido y un criterio filológico en el aspecto gramatical y léxico. Muchos países tienen esta institución, la Academia, que es la que codifica y norma el idioma, como también lo hace la escuela.

Pero ahora síganme Vds. y viajen conmigo a la Galicia de hace ciento cincuenta años; la Galicia en la que empiezan a escribir Rosalía de Castro, Curros Enríquez, Francisco Añón, Eduardo Pondal... El idioma gallego empieza a escribirse entonces, hace poco más de un siglo y medio. En aquellos momentos comienza en Galicia el movimiento de recuperación de la lengua y de la cultura gallegas que se conoce con el nombre de Rexurdimento (renacimiento).

Desde el comienzo mismo del Rexurdimento, se hicieron evidentes grandes diferencias en la escritura de nuestro idioma, reveladoras de la falta de unidad. Alberto Camino, Xoán Manuel Pintos, Francisco Añón, Xosé García Mosquera, Rosalía de Castro... escriben en gallego, una lengua que oyen, pero una lengua que no tiene reconocimiento oficial, que no está en la escuela ni codificada de ninguna manera: son músicos de oído. 
Esta es la situación cuando nace la literatura gallega contemporánea, en 1863, año en que se publica el libro fundacional de nuestra literatura, Cantares gallegos, de Rosalía de Castro. Diez años anterior, de 1853, es $A$ gaita gallega, de Xoán Manuel Pintos, pero este es un volumen misceláneo, no enteramente escrito en gallego. Naturalmente que el gallego, como todos Vds. saben, fue una lengua de cultura en la Edad Media (ejemplo de ello son las Cantigas de Santa María, de Alfonso X el Sabio, y nuestros tres cancioneros profanos). Pero cuando se inicia el Rexurdimento ninguno de estos cancioneros estaba editado y se había perdido, incluso, la memoria de esta tradición.

Los escritores del Rexurdimento -y esta es otra de sus proezas- escriben sin conciencia de su tradición cultural. Ninguno de ellos había leído ni conocía los cancioneros medievales. Los escritores no saben a qué atenerse: ignoran si la modalidad orensana es mejor que la modalidad luguesa; no hay criterios de propiedad y corrección y, sobre todo, no hay normas gráficas. La falta de unidad gráfica, morfológica y léxica -los tres pilares en los que se apoya la unidad del idioma- es percibida como anarquía.

El estado español tiene, desde 1713, la Real Academia Española, popularemnte conocida como la Academia de la Lengua, para codificar y normar, y tiene la escuela, que difunde la ortografía académica y enseña un epítome de la gramática de la Academia. Muy distinta es la situación de Galicia. Dentro de Galicia los escritores estaban a la intemperie. Así lo expresa Rosalía de Castro en el prólogo a sus Cantares gallegos (1863): "Sin gramática, nin regras de ninguna clas, o lector topará moitas veces faltas d'ortografía, xiros que disorarán ós oídos dun purisa, pro ó menos, e pra disculpar en algo estes defectos, puxen o maior coidado en reproducir o verdadeiro esprito do noso pobo e penso que o conseguín en algo...".

"Sin gramática, ni reglas de ninguna clase": así se encuentran los escritores que acometen la proeza de convertir el gallego, una lengua oral, en lengua de cultura. Algunos de estos escritores son conscientes de que tal criterio solo podría ser propuesto con eficacia desde una instancia supraindividual y ven en una Academia la futura solución a los conflictos lingüísticos.
Desde 1875 , en Galicia hay voces que reclaman la creación de una Academia. El primero fue el escritor orensano Valentín Lamas Carvajal. En la novena de sus Dez epístolas en verso escritas prós galegos dice Lamas Carvajal:

Falai na nosa melosiña fala pra que un tempo non chegue a facer morta; pobo infeliz que o seu linguaxe cala ten a ruína e perdición á porta Falai galego, pois non é mancilla, en Lugo, Ourense, Pontevedra e Cruña, cal castellano falan en Castilla.

Asina poderíamos un día, traballando costantes sin sosegó, fundar unha Academia, que faría o limpa, fixa e dá esplendor galego.

Como el de Lamas Carvajal hay otros muchos pronunciamientos de escritores gallegos, incluso de escritores gallegos que no utilizan el gallego como vehículo de expresión literaria. Es el caso, por ejemplo, de doña Emilia Pardo Bazán, destacada escritora gallega que siempre escribió en castellano. No obstante su práctica lingüística, a dona Emilia le parece necesaria una Academia gallega. Así lo dice en 1880: "la Academia de la lengua gallega, cuando se funde, que no escasean elementos para fundarla, ni a mí me faltará nunca constancia para seguir rogando a los que son capaces de constituirla, que se unan y limpien, fijen y den esplendor a esta habla"2.

Como vemos, cuando se reclama, en Galicia, una Academia se piensa siempre en el modelo de la Academia española, que tiene como divisa el conocidísimo tricápite "Limpia, fija y da esplendor". Tanto era el prestigio de esta institución, prestigio que hoy día se ha acrecentado más, si cabe, merced a la acertadísima gestión de sus últimos directores, el llorado Fernando Lázaro Carreter y el actual, Victor García de la Concha.

En 1895 (fallecida ya Rosalía de Castro, de cuyos tres grandes libros poéticos -Cantares gallegos, Follas novas y En las orillas del Sar-, el segundo, Follas novas, se publica en 1880, a cargo de la casa editorial "La Propaganda Literaria", de La Habana), en 1895, decimos, se intenta crear una Academia Gallega en Galicia, concretamente en La Coruña varios 
trabajos preparatorios: se circula propaganda, se buscan adhesiones y se llegan a redactar unos Estatutos. Cuando la creación de la Academia parece cosa hecha, los autoconvocados se disuelven y la anhelada institución no se llega a materializar.

¿Por qué fracasa esta Academia en 1895? Fracasa porque entre los intelectuales gallegos hay diferencias ideológicas y rencillas; por otra parte, quien está llamado a ser el presidente de la Academia, Manuel Murguía (que, como todos ustedes saben, fue historiador, autor de la Historia de Galicia, polígrafo muy importante, y marido de Rosalía de Castro, a quien animó a escribir y publicar en gallego), Manuel Murguía, decimos, a quien nadie discute su valía intelectual, tiene rasgos de carácter no siempre buenos para cohesionar.

Fue tanta la frustración que provocó este non nata Academia entre los intelectuales gallegos, que, durante, diez años, desde 1895 a 1905 , no se registra ningún otro pronunciamiento en favor de una institución de estas características.

Pero resulta que aquí en Cuba hay una persona, un humilde obrero, litógrafo de profesión, a quien nunca le sobró un peso, que no es universitario ni letrado, que vino a los seis años desde Ferrol, su ciudad natal, a La Habana, llamado José Fontenla Leal (1864-1919). Fontenla Leal es un amoroso coleccionista de libros gallegos y el promotor de dos iniciativas muy importantes para Galicia: una, el himno gallego, que escribió Pondal, con música de Pascual Veiga, y que se interpretó por primera vez en La Habana en 1907; la otra es la Academia Gallega, que se fundará, también, gracias a su decisión. Si el valor del himno es grande, por su simbolismo, mayor será la importancia de la Academia.

José Fontenla Leal tiene una inquietud cultural que logra transmitir a otro hombre extraordinario, que vive, en esos momentos, emigrado en La Habana. Me refiero al gran escritor gallego Manuel Curros Enríquez (1851-1908). De la conjunción de ambas voluntades, nacerá, el 1 de junio de 1905, en La Habana, la Asociación Iniciadora y Protectora de la Academia Gallega. Curros ostentará la presidencia de la institución y el secretario será el también escritor orensano Alfredo Nan de Allariz. Pero el verdadero motor de la Asociación, voluntariamente siempre en un egundo plano, fue José Fontenla Leal. El entusiasmo de Fontenla y el prestigio de Curros determinaron que se sumaran a la idea muchos gallegos residentes en Cuba.
Así, aunque la Real Academia Gallega se funda en La Coruña en 1906, en realidad se diseña en Cuba en 1905. Conscientes de que hay rencillas entre los intelectuales gallegos, la Iniciadora designa a Manuel Murguía y a otras personalidades indiscutibles para que constituyan, en Galicia, la Academia Gallega.

Las decisiones que llegaban de Cuba era imposible desacatarlas, porque venían con la música moral de la emigración, y con el prestigio ético e intelectual de José Fontenla y de Curros Enríquez.

La Asociación Iniciadora, pues, pone en marcha la Academia: designa a Murguía y a otros académicos fundadores; marca unas directrices de acción; y se compromete a cubrir las necesidades económicas de la puesta en marcha de la Academia.

La Academia Gallega es una academia tardía, puesto que nace en 1906 (se inaugura oficialmente el 30 de septiembre de 1906), pero hay que tener en cuenta que es la primera academia de una lengua no estatal que se crea en España. La Academia Gallega es anterior a otras dos instituciones españolas que nacen para normar lenguas que no son el castellano. Me refiero al Institut d'Estudis Catalans, que nacerá un año después (1907), en Cataluña, para entender en la norma del catalán, y a la Real Academia de la Lengua Vasca, Euskalzaindia, que nacerá en 1918, para hacer lo mismo con el vasco o eusquera.

La creación de la RAG suscita grandes expectativas en Galicia y fuera de ella. El día de su inauguración oficial en La Coruña, el 30 de septiembre de 1906, se leen innumerables adhesiones enviadas por intelectuales de dentro y de fuera del país. Entre ellas, destacamos la del erudito sueco Göran Bjorkman, quien dirige a la Academia un expresivo telegrama, concebido en estos términos: "Vivat, floreat natio Galaica" (Viva, florezca la nación gallega).

Fundada la RAG en La Coruña, la institución nacida en Cuba se sigue llamando AIYP, aunque funciona ya solo como Protectora, es decir, enviando dinero, fundamentalmente, y estimulando las actividades de la corporación en momentos difíciles. En cuanto a lo primero, no debemos cometer el error de pensar que la Academia Gallega se va a sostener con los fondos que envíen los terratenientes o los dueños de las zafras; muy al contrario, los miembros de la Iniciadora son, en su mayoría, personas como Fontenla Leal, de humildísima fortuna. 
Dicho todo esto, hay que preguntarse si los académicos fundadores de la Gallega, en Galicia, interpretaron correctamente a la Iniciadora. La AIYP marca unas directrices, la primera de ellas, la expresada en el lema latino de nuestra Academia: "Colligit, expurgat, innovatque" (es decir, Escoge, expurga e innova). No sabemos quien es el autor de este extraordinario tricápite: "Colligit, expurgat, innovatque", pero la fórmula, tan adecuada para definir la labor intelectual de una Academia de la lengua, procede de Cuba.

Tanto en este lema latino como en algunos otros textos emanados de la Iniciadora, es patente que, para los patriotas gallegos de Cuba, la Academia debe definirse, ante todo, como una academia de la lengua. Ahora bien, los académicos fundadores no siempre interpretaron correctamente a la Iniciadora. La lectura que se hace en Galicia, por parte de personas sabias, es una lectura en la que el acento no se pone en la lengua gallega. Por el contrario, los fundadores constituyen una academia de lo que entonces se llamaban Bellas y Buenas Letras.

Los invito a Vds. a comparar los textos, dos textos brevísimos: uno, emanado de la AIYP; el otro, de la RAG. En 1905 la AIYP establece la "...constitución... de la academia que ha de formar el Diccionario y la Gramática de nuestra lengua". En cambio, en 1906, en el artículo primero de sus Estatutos, dice: "El objetivo de la Academia, patrocinada por la Asociación Iniciadora y Protectora de la Academia Gallega, de la Habana, es cultivar las Bellas Letras en general, y principalmente aquellos estudios que más puedan contribuir al conocimiento de la Historia, Antigüedades, Literatura y Lengua de Galicia".

Como vemos, en la RAG hay contradicciones. Esto quedará de manifiesto, también, en el discurso inaugural de Manuel Murguía. En este discurso, Murguía dice lo siguiente: "Ellos (es decir, la AIYP) nos lo han dicho: quieren que empecemos por el estudio del idioma que hablamos hace más de diez siglos". Y añade: "Hacen bien: pueblo que olvida su lengua es un pueblo muerto". Sorprendentemente, este discurso lo pronuncia en castellano. Hay una contradicción evidente, pues, entre el pensamiento de Murguía y su praxis lingüística en castellano. Praxis habitual entre los intelectuales de la época. La misma Pardo Bazán había señalado esta paradoja, diciendo: "El gallego lo escriben quienes no lo hablan". Es decir, el gallego, para los intelectuales de esta época, era lengua editorial pero no lengua de instalación, no lengua de relación.
Cuba hizo mucho por la RAG: la puso en pie, la sostuvo en los años fundacionales, la alentó en los momentos difíciles...

Los 40 académicos fundadores hicieron mucho por la Academia. Hay que tener en cuenta que la condición de académico es meramente honorífica; nunca estuvo remunerada ni lo está ahora; a los académicos se les pedía -se les pide- que hagan un trabajo por el simple premio de servir a su país.

En un contexto de penuria económica, la RAG acomete una serie de actividades que, consideradas con la perspectiva del tiempo, nos parecen heroicas. Heroico es el que publiquen, desde el principio (20 de abril de 1906), el Boletín de la Academia Gallega, revista que ha sido importante en Galicia como órgano erudito y que hoy en día se sigue publicando. Desde el principio también, la Academia ha dedicado parte de sus fondos a reunir una Biblioteca y Hemeroteca que hoy día se reconocen, sin discusión, como las mejores del mundo en temas gallegos. La Academia ha promovido otras publicaciones, y participado y alentado actos de gran contenido simbólico, como la erección del monumento a Curros Enríquez, en La Coruña, obra de Asorey, el monumento más importante que existe en Galicia dedicado a un escritor. $\mathrm{Y}$ ahí siempre ha estado Cuba; pero téngase presente que los emigrantes sensibles a estos trabajos eran humildes y muchas veces su mayor aportación ha sido moral y de entusiasmo y pequeña la económica.

En cuanto al Diccionario gallego, hay que decir que desde el primer momento los fundadores emprenden los trabajos preparatorios para la obra, que se empieza a publicar, por fascículos, en 1913. La publicación continuará, a un ritmo muy lento, hasta 1928, año en el que se suspende definitivamente. El Diccionario se detiene simbólicamente, en la voz CATIVO (cativo, en gallego, significa pequeño).

La empresa del Diccionario fracasa, pues, y por varias razones. Por una parte, los fundadores no son filólogos, sino historiadores o aficionados a las Bellas Letras, y ninguno de ellos tiene experiencia en el trabajo lexicográfico... Por otra parte, la Academia no recibe otro apoyo económico que el de la AIYP, ya que, en Galicia, las ayudas son muy escasas, Las Diputaciones subvencionaban con una pequeñísima cantidad anual los trabajos académicos, pero esto era notoriamente insuficiente.

Así las cosas, el Diccionario queda interrumpido definitivamente. Desde entonces hasta 
el año 1990 aparecen buen número de diccionarios gallegos, todos sin el concurso de la Academia.

Forzoso es reconocer, pues, que quienes no hicieron lo necesario por la Academia en estos primeros tiempos, fueron las instituciones gallegas. Galicia no se portó bien. Durante muchos años, la RAG, vivió, fundamentalmente, de lo que aportaban los emigrados en Cuba. Ya en 1908, la Iniciadora lamentaba que la Academia no hubiese encontrado otros medios para su desarrollo que el apoyo de los gallegos de Cuba, elemento el menos numeroso y el más sacrificado.

Durante estos cien años, las dificultades que ha superado la RAG no han sido únicamente económicas. La Academia, desde los primeros días de su fundación, fue muy discutida. Todas las academias lo son. Es inevitable, dada la limitación de plazas, que siempre serán insuficientes para las personas que merecerían pertenecer a ella; consecuentemente, la selección de los candidatos provoca duras polémicas en los medios de comunicación.

La polémica se exacerban por razones políticas. La Academia ha estado sujeta a las vicisitudes políticas que han marcado la historia de España en los últimos cien años. La gran convulsión en la vida española y, consecuentemente, en la vida académica, ha sido la Guerra Civil española de 1936-1939 y sus perdurables consecuencias.

En este sentido, es capital reparar en que la Real Academia Gallega es la única institución gallega que ha sobrevivido a la Guerra Civil. En efecto, el triunfo de los nacionalistas, comandados por el general Franco, supuso la clausura de todos los partidos políticos, de todas las instituciones y empresas culturales gallegas.

Hay que recordar, a este propósito, lo sucedido con la institución más consciente y generosamente comprometida con la cultura gallega, el Seminario de Estudos Galegos, fundado en 1923, al que pertenecieron personalidades señeras como Castelao, Otero Pedrayo, Vicente Risco... Pues bien, el Seminario de Estudos Galegos fue clausurado y defenestrado por el régimen emanado de la Guerra Civil, y algunos de sus miembros, perseguidos. La palabra "defenestrado", además, es exacta: la Biblioteca del Seminario de Estudios Gallegos, en Santiago de Compostela, fue literalmente [tirada] por las ventanas a la calle... con la consiguiente pérdida de volúmenes y manuscritos preciosos.
Naturalmente, si la Academia sobrevivió a la Guerra Civil fue porque pagó un precio muy alto. El precio fue el de liquidar todos los aspectos no epidérmicos del galleguismo. Es decir, tras la Guerra Civil, la Academia ejerció lo que se llamaba "un galleguismo sano y bien entendido", o sea, un galleguismo superficial, epidérmico. Así, por ejemplo, la Academia no empleaba el idioma gallego en ninguna de sus actividades -internas ni públicas- ni demandaba tampoco la presencia del gallego en ninguna institución o ámbito de la sociedad.

La reorganización de la RAG tras la Guerra Civil se debe a la gestión de Manuel Casás, su presidente durante más de 20 años, desde 1936 a 1960. Casás fue un abogado de profesión, políticamente conservador, en quien los partidarios del levantamiento de Franco confiaban plenamente: buena prueba de ello es que el día 19 de julio de 1936, tras deponer al alcalde republicano de La Coruña, Alfredo Suárez Ferrín (que será fusilado), ofrecen el cargo de alcalde de la ciudad a Manuel Casás. Este, prudentemente, declina el ofrecido cargo.

Desde entonces, Manuel Casás ocupará un lugar relevante en la vida cultural coruñesa. Bajo su presidencia, la Academia se adhiere plenamente al nuevo régimen hasta el punto de nombrar al general Franco presidente de honor de la institución.

Para la continuidad de la Academia fue fundamental, como vemos, la personalidad de Casás y el rumbo que imprimió a la institución. Pero además, hubo algo que protegió a la Academia, y fue el carácter de "Real" que ostentaba la corporación gallega desde 1906, por concesión del rey Alfonso XIII. El título de "Real" ha significado siempre una salvaguarda para todas las Academias, también para la gallega; y no porque el régimen de Franco fuera monárquico (que no lo era), sino porque el título de "Real" otorgaba a estas instituciones patente de tradición; y el nuevo estado había surgido, según sus definidores, para respetar la esencia y tradición españolas. Así, el carácter de "Real" ha contribuido a que la Academia Gallega haya podido perdurar, pese a la Guerra y a momentos de acusada decadencia, y se mantenga en pie al cabo de un siglo.

Exiliados algunos académicos, enfermos o desaparecidos otros, Casás reorganiza, en lo posible, la corporación, que llevará, durante los años de posguerra, una vida vacilante, dedicada más a tareas representativas que propiamente académicas. No obstante, la pervivencia de la RAG fue altamente positiva: fue 
la única institución que sobrevivió a la Guerra Civil y, por lo tanto, permitió que en Galicia no se rompiese el hilo, por tenue que fuese, de la continuidad cultural.

A esta continuidad contribuye, en alguna medida, la AIYP de La Habana. La Protectora se había extinguido prácticamente tras la Guerra Civil y se reorganiza en 1947. La reorganización se produce bajo la presidencia de José Rubinos, jesuita gallego residente en La Habana, ciudad donde ejerció como profesor durante muchos años. Por cierto, que uno de sus alumnos fue Fidel Castro.

$\mathrm{Y}$ es que las relaciones entre Cuba y Galicia tienen múltiples y apasionantes aspectos. En el momento de la reorganización de la AIYP, en 1947, fue capital la labor del secretario, Antonio do Campo, orensano de origen, profesor de francés en La Habana y hombre muy activo en la Protectora. Rubinos y Do Campo mueven a los emigrantes gallegos y aglutinan a unos 400 socios, que contribuirán con su pequeña y agradecidísima aportación a las labores de la Academia.

Por este conducto sigue habiendo contactos entre Cuba y Galicia. Así, por ejemplo, nos es grato recordar, precisamente aquí, en este centro cultural, que en 1953 la escritora cubana Dulce María Loynaz viaja a España, al Congreso de Poesía que se celebra en Salamanca, y se acerca a La Coruña para conocer la Academia Gallega. En el archivo de la Academia se conserva la correspondencia que generó la visita de Dulce María Loynaz, que sería recibida por el presidente de la Academia.

La AIYP de la Academia en La Habana se extinguió en la década de los años sesenta. La asociación se había quedado sin socios (fueron muriendo todos los que la integraban), y la emigración gallega, aunque seguía siendo intensa, se dirigía a otros países. De manera que se fueron arbitrando otras medidas económicas en la propia Galicia.

En estos 100 años, la RAG ha tenido 10 presidentes, desde Manuel Murguía (el primero) a Xosé Ramón Barreiro Fernández (el actual), ambos historiadores. En los años finales del régimen de Franco, dirigen la RAG presidentes que no son afectos al franquismo, sino que entroncan con el galleguismo anterior a la Guerra Civil. Ejemplo de ello es Sebastián Martínez Risco, durante cuyo mandato (1960-1977) la Academia empieza a desarrollar tareas que van más allá de lo puramente representativo.
La iniciativa de mayor relevancia en este período ha sido la creación del Día das Letras Galegas, en 1963, cuando se cumplían cien años de la publicación de Cantares gallegos, de Rosalía de Castro, el primer libro contemporáneo escrito en gallego. El "Día das Letras Galegas", que este año cumple su cuadragésima tercera edición, es una iniciativa de extraordinaria relevancia. Cada 17 de mayo, en Galicia se celebra una fiesta cultural de exaltación del idioma, fiesta o conmemoración que cada año se dedica a un escritor. En tiempos muy precarios, en los que el gallego no tenía reconocimiento legal, el "Día das Letras Galegas" fue el paraguas que permitía organizar, cada 17 de mayo, una serie de actos en gallego o reivindicativos de la lengua y la cultura gallegas. En un espacio de nulas libertades, la instauración de este día tuvo una trascendencia extraordinaria. Por cierto, que este año 2005, el "Día das Letras Galegas" se dedica a un escritor gallego que nació en Cuba, a Lorenzo Varela (1916-1978).

Hoy día la RAG no es un club de notables, como lo ha sido en algún momento de su historia, sino un centro activo de trabajo lingüístico. En la actualidad, la RAG se ha constituido en una auténtica academia de la lengua, es decir, ha vuelto al espíritu de los fundadores: ha vuelto al espíritu de los patriotas que le dieron principio en la Habana. Cuando se creó, la Academia era el único ámbito de estudio científico y de promoción de la cultura y de la lengua gallegas: hoy comparte esa responsabilidad con el Gobierno de Galicia, con los trabajadores de todos los niveles de la enseñanza, con múltiples entidades culturales y con numerosas iniciativas.

La Constitución española de 1978 sancionó el castellano como la lengua española oficial del Estado y reconoció la cooficialidad del gallego, el catalán y el vasco en sus respectivas comunidades autónomas.

El Estatuto de Autonomía de Galicia (de 1981) y la Ley de Normalización Lingüística (de 1983) reconocen el gallego como lengua propia de Galicia, que todos los gallegos tienen el derecho de conocer y usar, y obligan a los poderes públicos a trabajar activamente en la promoción y defensa de la lengua y cultura gallegas.

La Ley de Normalización Lingüística (de 1983) reconoce a la RAG el criterio de autoridad en lo relativo a la norma, actualización y uso correcto de la lengua gallega. 
Este desarrollo legal, así como la presencia de otras muchas instituciones e iniciativas culturales, han permitido, como decimos, que la Academia Gallega se constituya como una auténtica academia de la lengua. Así se define en los vigentes Estatutos, los segundos que ha tenido la institución, que datan del año 2000 (Real Decreto 271/2000 de 25 de febrero). E1 artículo $1^{\circ}$ dice así: "A Real Academia Galega é unha institución científica que ten como obxectivo fundamental o estudo da cultura galega e especialmente a ilustración, defensa e promoción do idioma galego"

En este sentido, ha sido capital, para nuestro idioma, la promulgación de las llamadas Normas ortográficas e morfolóxicas do idioma galego (cuya primera versión data de 1982, y que ha sido revisada en el año 2000). Estas normas, elaboradas conjuntamente por la Academia Gallega y por el Instituto da Lingua Galega, de la Universidad de Santiago, han codificado el estándar del idioma gallego. También en colaboración con el Instituto da Lingua, la Academia ha publicado dos diccionarios (en 1990 y 1997), y, por último, la Gramática académica, anhelada por los iniciadores, va a aparecer próximamente.
En estos tres pilares se sustenta la unidad del idioma gallego.

Así pues, casi a las puertas de su centenario, la Academia Gallega ha vuelto al espíritu de sus promotores, los heroicos integrantes de la Asociación Iniciadora y Protectora de la Academia Gallega, nacida en La Habana el 1 de junio de 1905.

Para concluir, debo decir que, en estos cien años de existencia, la RAG ha visto nacer y morir a su lado numerosas empresas culturales, muchas de ellas conscientes y generosas. La RAG constituye un ejemplo de continuidad, de tenacidad en lo intelectual y en lo erudito, y de vinculación entre las diversas generaciones de mujeres y hombres de letras, en Galicia, desde los albores del siglo XX. Que exista esta institución, tan importante para Galicia, por sus trabajos científicos y por sus aspectos simbólicos y de permanencia, se debe, indudablemente, al esfuerzo y al trabajo de la Asociación Iniciadora y Protectora de la Academia Gallega, que nació en Cuba. Esto es lo que, próximos al 1 de junio de 2005, en que se cumplirán los 100 años de la creación de esa asociación, estamos obligados moralmente a recordar y a agradecer. Muchas gracias. 